\title{
PEMBUATAN WEBSITE KATALOG PRODUK UMKM UNTUK PENGEMBANGAN PEMASARAN DAN PROMOSI PRODUK KULINER
}

\section{WEBSITE CREATION PRODUCT CATALOG MSMEs FOR MARKETING AND PROMOTION DEVELOPMENT OF CULINARY PRODUCTS}

\author{
${ }^{1)}$ Ferry Rahmat Astianta Bukit, ${ }^{2)}$ Gea Geby A.S, ${ }^{3)}$ Irvan, ${ }^{4)}$ Fahmi \\ ${ }_{1), 2), 3), 4)}$ Fakultas Teknik, Universitas Sumatera Utara, Indonesia \\ Jl. Almamater, Kampus USU, Padang Bulan, Medan, Indonesia \\ Email : ferrybukit@usu.ac.id
}

\begin{abstract}
ABSTRAK
Dalam pengelolaannya IMO Sumut memiliki beberapa kekurangan, salah satunya yaitu kurangnya pengetahuan tentang penggunaan internet dan minimnya media pemasaran dan promosi. Selama ini IMO melakukan promosi dan pemasaran melalui hubungan antar teman dan mengikuti bazar diberbagi event. Tetapi kegiatan tersebut dirasa kurang maksimal karena saat ini perkembangan teknologi informasi semakin cepat, maka semakin banyak bidang yang bergantung pada teknologi informasi digital, salah satunya yaitu Website. Oleh karena itu, tujuan dari kegiatan ini yaitu untuk meningkatkan pengetahuan dan kemampuan IMO Sumut dalam memasarkan produk UMKM melalui internet dan mampu mengelola website sebagai media promosi. Untuk mencapai tujuan tersebut maka metoda yang digunakan adalah difusi iptek dalam pembuatan website katalog produk UMKM, serta sosialisasi dan pelatihan pemanfatan internet dan pengelolaan website. Hasil dari pelaksanaan kegiatan ini yaitu berupa website www.imosumut.com. Adanya peningkatan jumlah pelanggan secara signifikan pada bulan ke-4,5, dan 6. Hasil sosialisasi dan pelatihan menunjukkan terjadi peningkatan pemahaman mitra dalam menggunakan serta memanfaatkan internet sebagai media pemasaran rata-rata sebesar $76 \%$.
\end{abstract}

Kata kunci: UMKM; Makanan Olahan; Website; Pemasaran; Promosi

\begin{abstract}
In its management IMO North Sumatra has several shortcomings, one of which is the lack of knowledge about internet use and the lack of marketing and promotional media. So far, IMO has been promoting and marketing through relationships between friends and taking part in bazaars in various events. But these activities are felt to be less than optimal because currently the development of information technology is getting faster, so more and more fields are dependent on digital information technology, one of which is the Website. Therefore, the purpose of this activity is to improve North Sumatra's IMO knowledge and capability in marketing MSMEs products through the internet and being able to manage websites as a promotional medium. To achieve these objectives, the method used is the diffusion of science and technology in making the MSMEs product catalog website, as well as the socialization and training of internet utilization and website management. The results of this activity are in the form of the website www.imosumut.com. There was a significant increase in the number of customers in months 4.5 and 6 . The results of the socialization and training showed an increase in understanding of partners in using and utilizing the internet as a marketing medium by an average of $76 \%$.
\end{abstract}

Keywords: MSMEs; Processed Foods; Website; Marketing; Promotion

Submitted : 18 April 2019 Revision : 21 Juni 2019 Accepted : 20 Juli 2019 


\section{PENDAHULUAN}

Dalam perekonomian Indonesia UMKM merupakan kelompok usaha yang memiliki jumlah paling besar dan terbukti tahan terhadap berbagai macam goncangan krisis ekonomi (Ragimun, Sudaryanto, \& Wijayanti, 2015). UMKM berperan penting dalam pembagunan ekonomi, pengurangan kemiskinan, dan pembukaan lapangan kerja di negara berkembang(Tarutė \& Gatautis, 2014).

Kriteria usaha yang termasuk dalam Usaha Mikro Kecil dan Menengah telah diatur dalam payung hukum. Berdasarkan Undang-Undang Nomor 20 Tahun 2008 tentang Usaha Mikro, Kecil dan Menengah (UMKM) ada beberapa kriteria yang dipergunakan untuk mendefinisikan pengertian dan kriteria Usaha Mikro, Kecil dan Menengah(Kementerian Hukum dan HAM, 2008).

Ikatan Makanan Minuman Olahan Sumatera Utara yang disingkat dengan IMO Sumut merupakan organisasi bermula dari ide beberapa pelaku Usaha Mikro Kecil dan Menengah (UMKM) sekitar tahun 2008 membentuk kelompok yang khusus pada produk kuliner. Berbagai macam kegiatan dan pelatihan telah mereka dapatkan dari berbagai instansi Pemerintahan seperti kegiatan pelatihan dari Dinas Perdagangan dan Perindustrian Provinsi Sumatera Utara, Dinas Koperasi dan UMKM Provinsi Sumatera Utara, Dinas Pariwisata serta berbagai Perusahaan BUMN lainnya.

Seiring berjalannya waktu dan banyaknya anggota yang bergabung serta tertib organisasi, pada awal tahun 2018 organisasi IMO melalui Notaris Mulkan Hariadi Siregar, SH mendirikan organisasi IMO sesuai akta Notaris no. 6 tanggal 20 Maret 2018.

Saat ini anggota IMO resmi yang terdaftar sebanyak 66 pelaku UMKM yang tersebar di 3 kabupaten/Kota di Sumatera Utara terdiri dari Kota Medan, Deli Serdang dan Kabupaten Simalungun. Ditargetkan sampai akhir 2018 IMO dapat membuka cabang minimal 5 cabang di kabupaten/ Kota di Sumatera Utara diantaranya Binjai, Sedang Berdagai, Sibolga, Langkat dan Pematang Siantar.

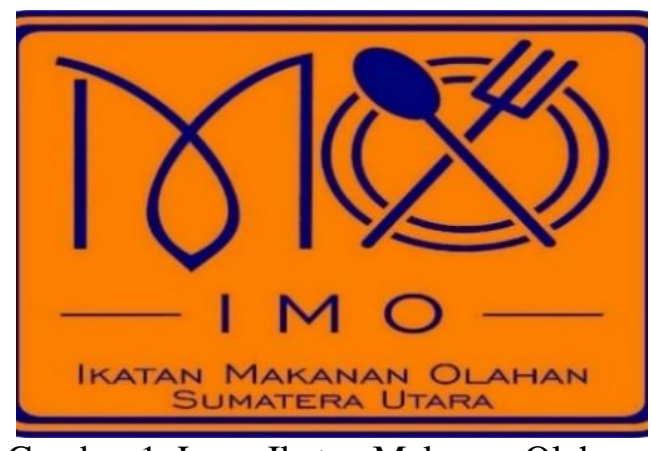

Gambar 1. Logo Ikatan Makanan Olahan Sumatera Utara

Adapun Visi dan Misi dari IMO Sumut adalah :

VISI

Terwujudnya organisasi IMO, Usaha Mikro Kecil dan Menengah menjadi Lembaga yang Tumbuh dan Berkembang secara Sehat, Tangguh dan Mandiri dengan Tingkat Daya Saing yang Tinggi sehingga dapat berperan sebagai Pelaku Utama dalam Perekonomian provinsi sumatera utara yang bertumpu pada Mekanisme yang Berkeadilan dan menjadi Fasilitator yang memiliki Kompetensi tinggi.

MISI

1) Mempromosikan keberadaan imo dan mengenalkannya kepada masyarakat luas di sumatera utara khususnya kota medan

2) Mempromosikan \& memasarkan produk-produk hasil produksi mandiri dari anggota imo

3) Mempererat tali silaturahim antara sesama pengurus, anggota imo dan juga masyarakat sebagai pelanggan

Berikut merupakan Gambar Produk Makanan Olahan dari IMO Sumut. 
Gambar 2. Produk-Produk IMO

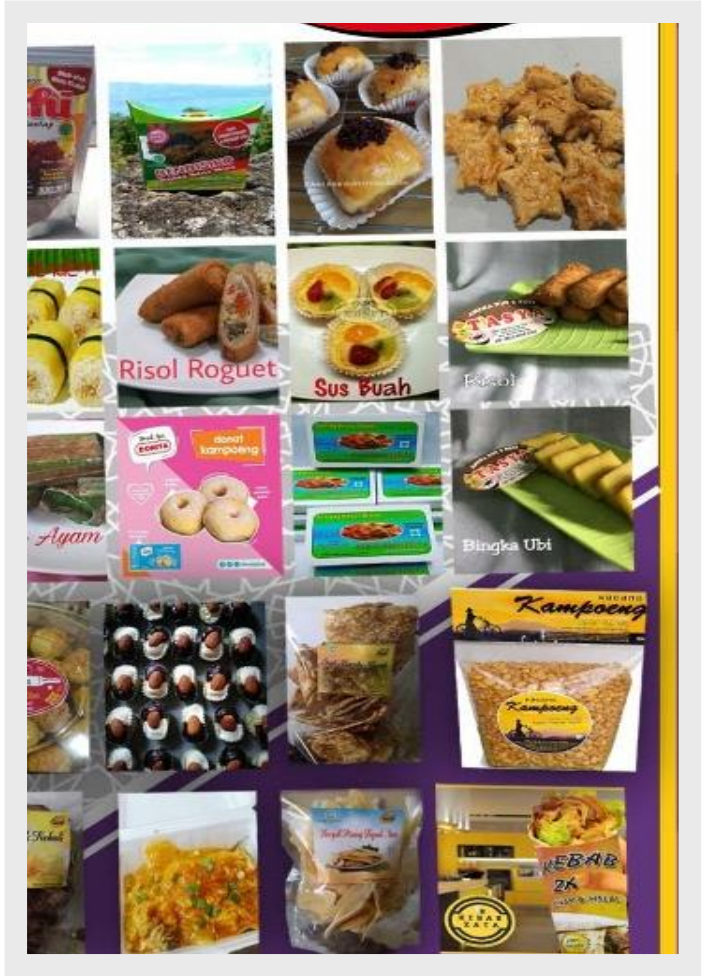

Pemberdayaan UMKM di tengah arus globalisasi dan tingginya persaingan membuat UMKM harus mampu mengadapai tantangan global, seperti meningkatkan inovasi produk dan jasa, pengembangan sumber daya manusia dan teknologi, serta perluasan area pemasaran. Hal ini perlu dilakukan untuk menambah nilai jual UMKM itu sendiri, utamanya agar dapat bersaing dengan produk-produk asing yang kian membanjiri sentra industri dan manufaktur di Indonesia, mengingat UMKM adalah sektor ekonomi yang mampu menyerap tenaga kerja terbesar di Indonesia(Sudaryanto, 2011).

Pengunaan Sistem Informasi (SI) dan Teknologi Informasi (TI) oleh UMKM merupakan suatu hal yang menarik untuk diketahui. Dimana sistem dan teknologi tersebut disebut sebagai penggerak pembangunan yang memegang peranan penting dalam pertumbuhan berkelanjutan dalam suatu organisasi bisnis.(Siregar, 2008).

Saat ini dikenal dengan era digitial firm dimana Sistem Informasi yang secara luas banyak digunakan adalah internet. Internet menyediakan platform terknologi universal baru dimana kita dapat membangun semua jenis produk baru, pelayanan, strategis, dan organisasi. Internet juga mengubah cara-cara Sistem Informasi digunakan dalam bisnis dan kehidupan sehari-hari(Laudon \& Laudon, 2003).

Internet menawarkan banyak kemungkinan baru untuk melakukan bisnis, kemampuan internet yang dikenal dengan World Wide Web merupakan perhatian khusus bagi organisasi.

Globalisasi ekonomi mendorong banyak perusahaan untuk melakukan perubahan agar bisa tetap hidup. Untuk berkompetisi dalam pasar global, banyak UKM butuh untuk mengembangkan strategi bisnis baru dan menggunakan teknologi baru (Caldeira \& Ward, 2001).

Empat perubahan global telah mengubah lingkungan bisnis. Perubahan pertama kehadiran dan penguatan ekonomi global. Perubahan kedua adalah transformasi ekonomi dan masyarakat industri ke dalam ekonomi pelayanan berbasis informasi dan pengetahuan. Perubahan ketiga adalah transformasi usaha bisnis. Perubahan keempat adalah hadirnya digital firm. Akan tetapi UMKM pada umumnya memiliki sumberdaya manusia dan keuangan yang terbatas, sehhingga kemungkinan kurang siap untuk melakukan perubahan(Caldeira \& Ward, 2001).

Permasalahan utama yang muncul pada Ikatan Makanan/Minuman Olahan (IMO) sebagai mitra pengabdian adalah belum mampu memanfaatkan teknologi Sistem Informasi berbasis internet sebagai media promosi pemasaran produk UMKM.

Berdasarkan permasalahan tersbut maka melalui pengabdian masyarakat yang merupakan salah satu tri dharma perguruan tinggi, kami melakukan kegiatan pembuatan website sebagai media, sarana maupun prasarana dalam pemasaran dan promosi produk-produk UMKM IMO SUMUT dan juga memberi sosialisasi serta pelatihan penggunaan internet serta pengelolaan website sebagai media pemasaran yang mudah dan luas. 


\begin{abstract}
Adapun tujuannya yaitu dengan adanya pembuatan website beserta sosialisasi dan pelatihan, diharapkan dapat meningkatkan pengetahuan mitra dalam menggunakan dan memasarkan produkproduk nyamelalui internet dan mampu mengelola website sebagai media promosi.
\end{abstract}

\section{METODE}

Metode yang digunakan adalah berupa difusi iptek dalam pembuatan website katalog produk-produk UMKM bagi mitra pengabdian, serta sosialisasi dan pelatihan untuk dapat memanfaatkan internet dan mengelola website sebagai media pemasaran.

Untuk melihat keberhasilkan kegiatan dan ketercapaian tujuan dari kegiatan ini maka dilakukan evaluasi. Evaluasi yang dilakukan mencakup evaluasi pemanfaatan website sebagai media promosi dan evaluasi peningkatan pemahaman mitra terhadap penggunaan internet.

Kegiatan pengabdian ini melibatkan satu kelompok mitra Ikatan Makanan Minuman Olahan (IMO) Sumatera Utara.IMO Sumut merupakan organisasi yang terbentuk sekitar tahun 2008. Dimana pada awal tahun 2018 organisasi IMO melalui Notaris Mulkan Hariadi Siregar, SH mendirikan organisasi IMO sesuai akta Notaris no. 6 tanggal 20 Maret 2018.

Saat ini IMO yang diketuai oleh Ibu Sujiane telah memiliki anggota resmi yang sebanyak 66 pelaku UMKM yang tersebar di 3 kabupaten/Kota di Sumatera Utara terdiri dari Kota Medan, Deli Serdang dan Kabupaten Simalungun.

\section{HASIL DAN PEMBAHASAN}

Berdasarkan metode yang dilakukan dan berkoordinasi dengan kelompok mitra, maka dapat diidentifikasi rancangan website yang sesuai dengan kebutuhan mitra sehingga mengasilkan website dengan domain www.imosumut.com. Website tersebut dapat dimanfaatkan oleh para pelaku UMKM yang tergabung di dalam Ikatan Makanan Minuman Olahan Sumatera Utara (IMO Sumut) dalam memasarkan produk-produknya. Gambar berikut merupakan tampilan website yang dihasilkan.

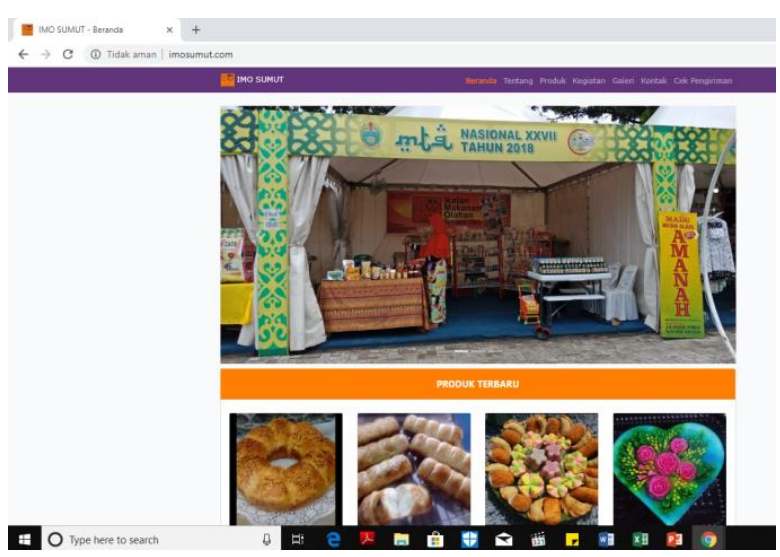

Gambar 3. Beranda Website Imo Sumut

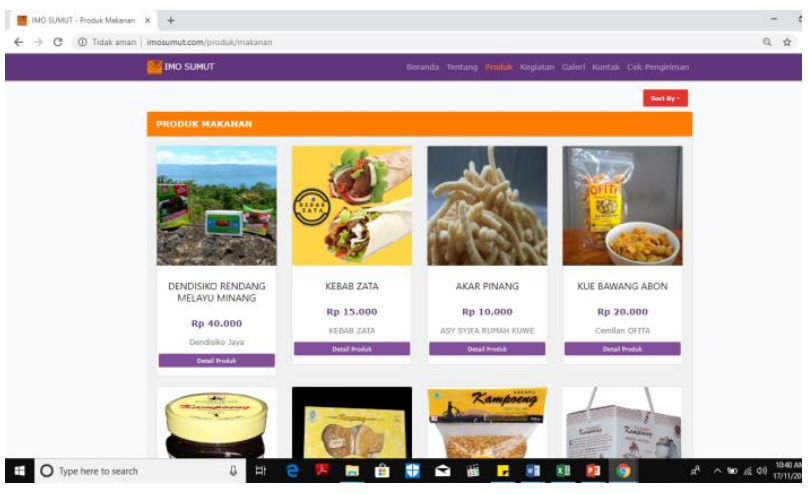

Gambar 4.Tampilan Produk Makanan IMO Sumut

Adapun Tahapan-tahapan yang dilakukan dalam pembuatan website IMO Sumut dapat dijabarkan sebagai berikut :

1. Membuat Use Case Diagram

Use Case diagram diperlukan untuk menentukan fitur apa saja yang dibutuhkan oleh pengguna website yang akan dibangun. Sehingga proses pengerjaan menjadi lebih terukur dan terarah. 


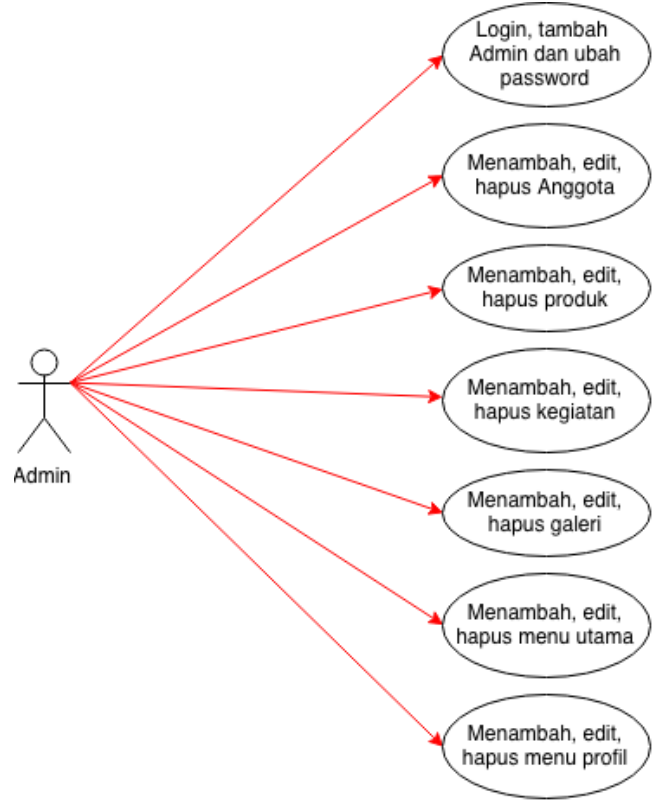

Gambar 5. Use Case Diagram

2. Membuat Activity Diagram Activity diagram berguna untuk mengetahui logic flow dari penggunaan website yang akan dibangun.

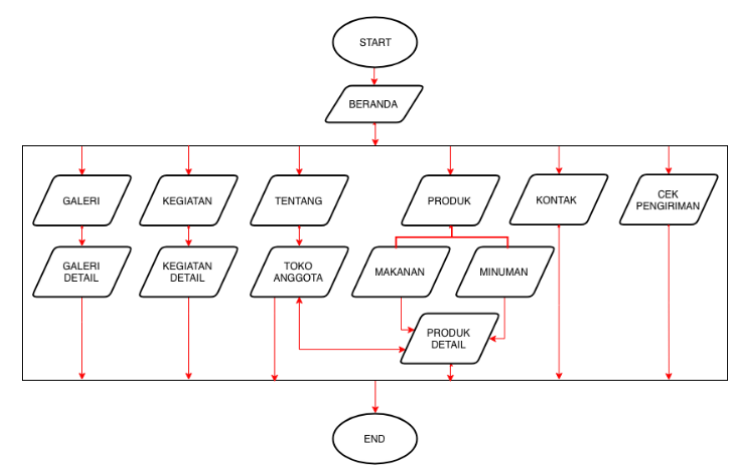

Gambar 6. Activity Diagram

3. Merancang Database Menggunakan Entity Relationship Diagram (ERD).

ERD berguna untuk memudahkan pengembang dalam membangun database pada suatu website serta relasi antar table pada suatu database. Database sendiri berguna untuk menyimpan data yang diperlukan pada suatu website.

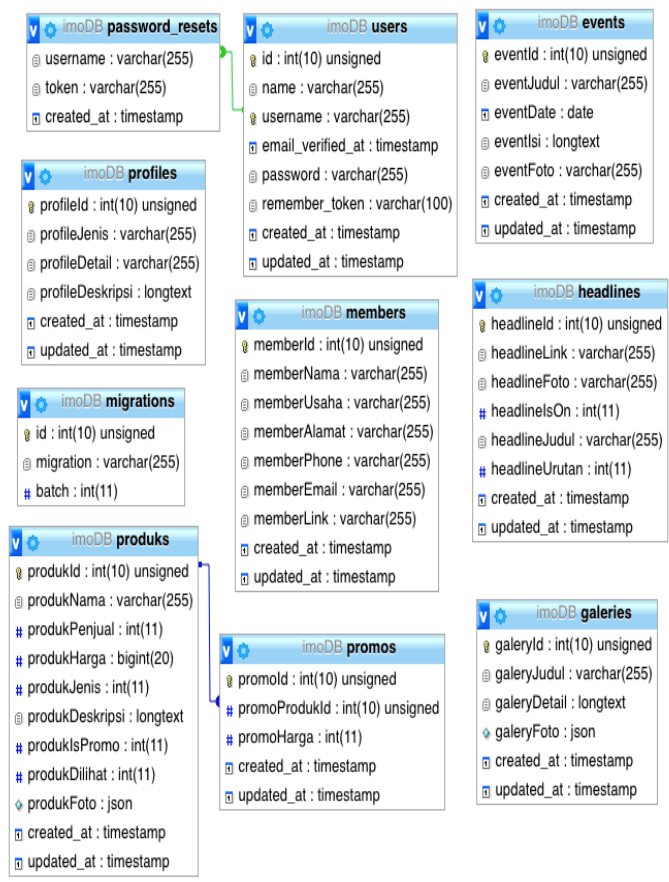

Gambar 7. ERD website IMOSUMUT

4. Merancang User Interface (UI)

User interface berguna sebagai media komunikasi antara pengguna dengan sistem yang terdapat pada website.

Perancangan user interface berguna sebagai landasan developer dalam membangun tampilan website yang diharapkan. Berikut merupakan gambaran tampilan-tampilan website IMO Sumut.

5. Membangun website

Website yang dibangun menggunakan PHP 7.1, MySQL, Blade, Bootstrap, javascript, dan Apache. Sedangkan software yang digunakan diantaranya: PhpStorm, Chrome, VirtualBox, Homestead, Vagrant, dan Filezilla.

Evaluasi dari kegiatan difusi iptek dalam pembuatan website dapat dilihat pada grafik berikut ini. 


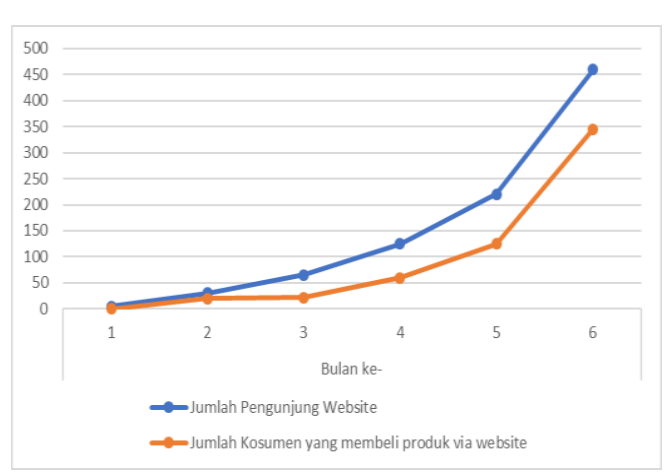

Gambar 7. Grafik Hasil Evaluasi

Penggunaan Website Sebagai Media

Pemasaran

Berdasarkan hasil evaluasi penggunaan website dapat dilihat terjadi peningkatan jumlah pengunjung website dan juga jumlah konsumen yang membeli produk melalui website secara signifikan pada bulan ke-4,5, dan 6. Hal ini dikarenakan sudah semakin banyaknya produk-produk yang dipromosikan pada website tersebut. Dengan meningkatnya jumlah pengunjung yang mana akhirnya berimbas kepada peningkatan jumlah pelanggan. Dengan meningkatnya jumlah pelanggan tentu juga berimbas pada meningkatnya jumlah penjualan. Peningkatan penjualan dapat memberikan keuntungan yang lebih tinggi(Pearce \& Robinson, 2013).

Sosialisasi dilakukan kepada 20 orang anggota mitra terkait penggunaan internet dalam pemasaran produk-produk UMKM yang instan dan luas. Sosialisasi meliputi informasi pentingnya teknologi internet, cara mengakses internet, cara memasarkan produk melalui internet, cara membuat desain dan foto produk yang menarik, dan cara membeikan informasi produk pada internet.

Pelatihan dilakukan untuk mengedukasi mitra terkait pengelolaan website dan sistem pemasaran melalui website. Pelatihan yang dilaksanakan menggunakan metode experimential learning, yang artinya melibatkan peserta secara aktif di setiap sesi pelatihan sehingga peserta belajar dan mengalami secara langsung untuk setiap proses.
Pelatihan dalam hal pengelolaan website dilakukan hanya kepada anggota mitra yang ditugaskan sebagai admin pengelola website. Pelatihan dimulai dengan memberikan pengetahuan dan pemahaman tentang internet, login kedalam website dengan akun, menambah atapun menghapus informasi produk dalam website, menambah foto, dan lain sebaginya sampai admin benar-benar mampu mengelola website tersebut secara bekelanjutan.

Selama mengikuti sosialisasi dan pelatihan, para peserta terlihat antusias dan aktif dalam menerima materi serta diskusi dan praktek yang dilakukan. Semakin peserta pelatihan berpartisipasi aktif dalam kegiatan pelatihan maka semakin banyak pengetahuan yang dimiliki karena semakin banyak informasi yang diperoleh dan dapat diterapkan secara langsung dalam kegiatan(Sardi \& Pulungan, 2019).

Evaluasi dari kegiatan sosialisasi dan pelatihan didapatkan bahwa terjadi peningkatan pemahaman mitra terkait penggunaan internet yang hasil tersebut direpresentasikan pada gambar grafik berikut.

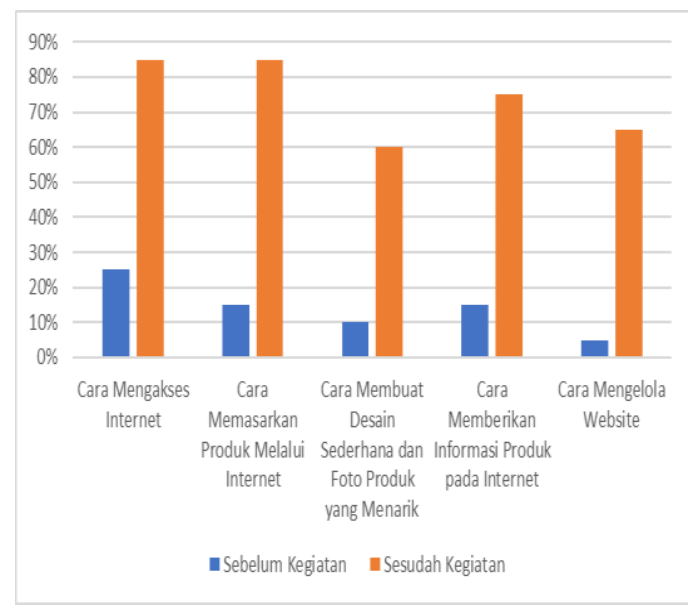

Gambar 8. Grafik Hasil Evaluasi Kegiatan Sosialisasi dan Pelatihan

Berdasarkan hasil evaluasi kegiatan sosialisasi dan pelatihan, peningkatan pengetahuan dan kemampuan mitra yang terbesar ada pada cara mengakses internet, dan cara memasarkan 
prduk melalui internet. Penerapan teknologiinternet dapatmembantu meningkatkan omset dan perluasan usaha(Harto, Pratiwi, Utomo, \& Rahmawati, 2019).Sementara peningkatan pengetahuan dan kemampuan mitra dalam hal cara memberikan infomasi produk, cara mengelola website, cara membuat desain dan foto produk, tidak terlalu signifikan. Hal ini dikarenakan dibutuhkannya pengetahuan dan kemampuan dalam menggunakan software editing foto, juga dibutuhkan kreativitas dan inovasi dalam membuat desain, foto, maupun infomasi yang menarik.

\section{SIMPULAN}

Kesimpulan dalam pelaksanaan kegiatan Program Pengabdian Kepada Masyarakat ini yaitu Website www.imosumut.com merupakan media yang dapatdigunakan untuk memperluas dan mempermudah mitra dalammempromosikan dan memasarkan produk-produk UMKM anggota Ikatan Makanan Minumam Olahan (IMO) SUMUT.Selain daripada itu kegiatan sosialisasi dan juga pelatihan yang dilakukan dapat meningkatkan pengetahuan dan kemampuan mitra dalam memanfaatkan internet sebagai media promosirata-rata sebesar $76 \%$.

\section{UCAPAN TERIMAKASIH}

Penulis mengucapkan terimakasih kepada Lembaga Pengabdian Kepada Masyarakat (LPM) Universitas Sumatera Utara (USU) dan Fakultas Teknik Universitas Sumatera Utara (USU), yang telah memberikan dukungan finansial terhadap kegiatan Pengabdian Kepada Masyarakat. Terimakasih kepada IMO SUmut sebagai Mitra dalam kegiatan PKM yang telah ikut berpartisipasi dan bekerjasama dalam pelaksanan kegiatan.

\section{DAFTAR PUSTAKA}

Caldeira, M., \& Ward, J. (2001). Using Resource-Based Theory To Interpret the Successful Adoption and Use of Information Systems \& Technology in Manufacturing Small and Medium
Sized Enterprises. The 9th European Conference on Information Systems, 1159-1169.

https://doi.org/10.1057/palgrave.ejis. 3000454

Harto, D., Pratiwi, S. R., Utomo, M. N., \& Rahmawati, M. (2019). Penerapan Internet Marketing Dalam Meningkatkan Pendapatan Pada UMKM. Jurnal Pengabdian Dan Pemberdayaan Masyarakat, 3(1), 39-45.

Kementerian Hukum dan HAM, I. (2008). Undang-Undang No 20 Tahun 2008 Tentang Usaha Mikro, Kecil, Menengah. (20), 1-24.

Laudon, \& Laudon. (2003). Management information systems: managing the digital firm. In Revista de Administração Contemporânea (Vol. 7). https://doi.org/10.1590/S141565552003000100014

Pearce, J. ., \& Robinson, R. . (2013). Strategic Management: Formulation, Implementation, and Control Manajemen Strategis (12th) (12th ed.). Jakarta Selatan: MC Graw Hill.

Ragimun, Sudaryanto, \& Wijayanti, R. R. (2015). Strategi Pemberdayaan UMKM Menghadapi Pasar Bebas Asean. Web Kementerian Keuangan, $1-32$.

Sardi, J., \& Pulungan, A. B. (2019). Pelatihan reparasi dan perawatan alat listrik rumah tangga untuk pemuda pesisir. Jurnal Pengabdian Dan Pemberdayaan Masyarakat, 3(1), 36.

Siregar, A. R. (2008). Penggunaan Sistem dan Teknologi Informasi Untuk Usaha Kecil dan Menengah. Universitas SUmatera Utara, 1-13.

Sudaryanto. (2011). The need for ICT education for managers or agribusinessmen for increasing farm income: Study of factor influences on computer adoption in East Java farm agribusiness. International Journal 
of Education and Development Using Information and Communication Technology (IJEDICT), 7(1), 56-67.

Tarute, A., \& Gatautis, R. (2014). ICT Impact on SMEs Performance. Procedia - Social and Behavioral Sciences, 110, 1218-1225. https://doi.org/10.1016/j.sbspro.2013 .12 .968 